\title{
Expired Air Carbon Monoxide Levels as a Marker of Passive Smoking In Pregnant Women
}

\author{
Amareswari V.H. ${ }^{1}$, Padma K. ${ }^{2}$ \\ ${ }^{1}$ Assistant Professor, Dept of Physiology, Rajarajeswari Medical College, Bengaluru, \\ ${ }^{2}$ Redt Prof and Director, Dept of Physiology, Madras Medical College, Chennai, Tamilnadu
}

\begin{abstract}
Background and Aim: Smoking directly or indirectly has serious impact on health of an individual. During smoking various chemicals and toxic substances are released into the air such as nicotine, carbon monoxide which can be inhaled by the people nearby indirectly. Pregnant mothers may passively inhale carbonmonoxidewhen exposed to such environment. Maternal Carbon monoxide passes through placenta and enters foetalblood combine with foetalhaemoglobin forming foetal carboxy haemoglobin. Foetal carboxy haemoglobin in turn makes oxygen unavailableto foetal tissues which could be the reason for various poor outcomes in unborn foetus such as low birth weight, intra uterine growth retardation with higher rates of perinatal mortality. This study is aimed at measuring the expired air carbon monoxide levels in passively smoking pregnant women that can be correlated with exposure to passive smoking.
\end{abstract}

Method and Materials: 100 antenatal women of gestational age between 26 to 34 weeks with and without exposure to passive smoking were measured for carbon monoxide levels in their expired air usingsimple, portable non invasive carbon monoxidemonitor.

Statistical Analysis: Data analysis was done with unpaired student $t$ test. P value of $<0.05$ was taken to be significant.

Results: No significant statistical difference is observed between cases and control groupsin expired aircarbon monoxide levels.

Discussion and Conclusion: The lesser half life of carbon monoxide in exhaled air. The longtime interval between the exposure and the time of testing, the metabolic changes associated with pregnancy could have made this test inconclusive. Though gold standard blood analytic method cannot be replaced by this breath monitors, it can be used as a simple portable noninvasive toolto educate pregnant women to avoid exposure to passive smoking.

Keywords: Expired air carbon monoxide, pregnant women, passive smokers, foetal carboxy haemoglobin.

\section{Introduction}

According to the international consultation on environmental tobacco smoke (ETS) and child health,

\section{Corresponding Author:}

\section{Dr. Amareswari V.H.}

Assistant Professor, Dept of Physiology, Rajarajeswari Medical College, Bengaluru, e-mail: amareswarivh@gmail.com maternalsmoking is associated with many harmful effects on the outcome of unborn foetus. Low birth weight and growth retardation are common complications ${ }^{1}$. There is also $33 \%$ increase in perinatal mortality, $50 \%$ increase in idiopathic mental retardation. Other complications include sudden infant death syndrome ${ }^{2}$, attention deficit hyperactivity disordersand premature delivery. The components emitted during smoking cross the placenta and act as mutagens resulting in childhood cancers like acute lymphocytic leukemia and lymphoma ${ }^{3}$. In countries like India though maternal smoking is not as common 
as western countries indirect exposure to smoking is not uncommon. There is evidence thatpassively smoking pregnant women show harmful effects on outcome of pregnancy as those of smokingmothers. These includemiscarriage, stillbirth, congenital malformations, low birth weight, intrauterine growth retardation, sudden infant death syndrome, and preterm delivery ${ }^{4}$.

The so called passive smoker inhale the side stream smoke arising from burning end of the cigarette which contributes to $85 \%$ of smoke present in the room. This side-stream smoke appears to have the lethal toxic gases in considerably higher concentrations than in the mainstream smoke ${ }^{5}$. Carbon monoxide and nicotine are the common gases emitted during smoking. On average $4 \%$ carbon monoxide is present in cigarette smoke ${ }^{6}$. In a smoke filled room a non smoker is exposed to 25-100 ppm carbon monoxide.

Carbon monoxide combines with maternal haemoglobin and form carboxy haemoglobin which in turn crosses the placenta and leads to foetal hypoxia. Nicotine in the smoke causes vasoconstriction aggravating foetal hypoxia. Nicotinic effects may be due to inappropriate stimulation of nicotine cholinergic receptors and its neuroteratogenicity ${ }^{7}$.

Carbon monoxide is a colourless, odourless gas produced from incomplete combustion of fossil fuels. Exhaust fumes from the vehicles, malfunctioning heaters, poorly ventilated fires and exposure to tobacco smoke are some of the commonest sources of carbon monoxide production. It enters the body mainly by inhalation. Haemmetabolism contributes to some of its endogenous production ${ }^{8}$. Carbon monoxide dissolves in the plasma and binds with haemoglobin, the oxygen transporting pigment.It has high affinityfor haemoglobin about 240 times that of oxygen,shifting oxygen dissociation curve to left ${ }^{9}$. This results inunavailability and utilization of oxygen by the tissues. In foetus the affinity is still more about 172 times. This accounts for at least some of its toxic effects ${ }^{10,11}$.There is a close relationship between concentration of carbon monoxide in the expired air andmaternal bloodcarboxyhaemoglobin $\left(\begin{array}{ll}\% & \mathrm{COHb}\end{array}\right)$ concentration $^{12}$.

The carbon monoxide is eliminated in exhaled breath due to dissociation of carboxyhaemoglobin allowing free carbon monoxide to be present in the expired air. This can be employed in estimating carbon monoxidelevels in the blood by indirectly measuring exhaled $\mathrm{CO}^{13}$.Also there is a direct link between the level of $\mathrm{CO}$ in an expectant mother's breath and the level of $\mathrm{CO}$ in her unborn foetus blood. This is known as "Fetal carboxyhaemoglobin" $(\% \mathrm{FCOHb})^{14}$. Proportion of $\mathbf{F C O H b}$ levelis higher when compared to maternal $\mathrm{COHb}$.This level has been found to be on average 1.8 times higher in the baby than in the mother ${ }^{15}$

Various method are used to assess smoking exposure such as assays of cotinine (the major metabolite of nicotine) in urine and blood, hair nicotine, breath carbon monoxide analysis and self reporting.Measure of expired air carbon monoxide levels is a rapid, noninvasive and cheap method to assess exposure to passive smoking and can be used safely for antenatal clinic settings ${ }^{16}$. Breath $\mathrm{CO}$ monitors measure carbon monoxide in parts per million (ppm) in expired air and display breath concentration of $\mathrm{CO}$ reading along with its corresponding blood concentrationlevels.

Therefore, the present study is aimed at measurement of expiredair carbon monoxide level (ppm) in passive pregnant smokers and corresponding \% carboxy haemoglobin level (blood $\mathrm{CO}$ ) using the non invasive Carbon monoxide check + instrument.

\section{Materials and Method}

\section{Study Design: Prospective case control study}

This study conducted in August 2014 in Govt Egmorematernity hospital after institutional ethics clearance. 100 pregnant women in the gestational age group between 26-34 weeks were selected randomly from morningantenatal clinic and classified into 2 groups those exposed to passive smoking (Exposure to other people's tobacco smoke) and those not exposed to passive smoking. Inclusion criteria for study selection: Pregnant women with gestational age 26-34 weeks (exposed as well as non exposed to passive smoking) Exclusion Criteria: Pregnant women who are active smokers, those exposed to cooking wood fire, known chronic obstructive pulmonary disease, pulmonary tuberculosis, acute or Chronic lung diseases, and other maternal related or general illness. All the participants included were informed about the study and a written and informed consent were obtained from them. They were subjected to complete general and systemic examination. The study and control group were subjected to non invasive assessment of expired air $\mathrm{CO}$ levels using $\mathrm{CO}$ check + instrument. After comfortably seated in the chair for a while the subjects were asked to inhale 
deeply, hold the breath for $15 \mathrm{sec}$ and exhale slowly into the disposable mouth piece attached to the $\mathrm{CO}$ check + instrument. Breath carbon monoxide reading were noted and reported as parts per million (ppm) .The CO Check + instrument detect carbon monoxide gas by means of an electrochemical gas sensor. They incorporate a graphic LCD displayer that display the carbon monoxide concentration level in a numerical format and/or colored indicators that correspond to various concentration ranges like green 0-6 ppm indicates no exposure, yellow 7-10ppm indicates mild -moderate exposure andred 10-20ppm indicates severe exposure. The \% $\mathrm{COHb}$ along with the results of $\mathrm{CO}$ she passed on to her unborn baby were also displayed in \% FCOHbor foetalcarboxyhaemoglobin. All measurements were backed up with an appropriate colour code to show the risk of exposure. The sensitivity of the instrument is as low as $1 \mathrm{ppm}$.

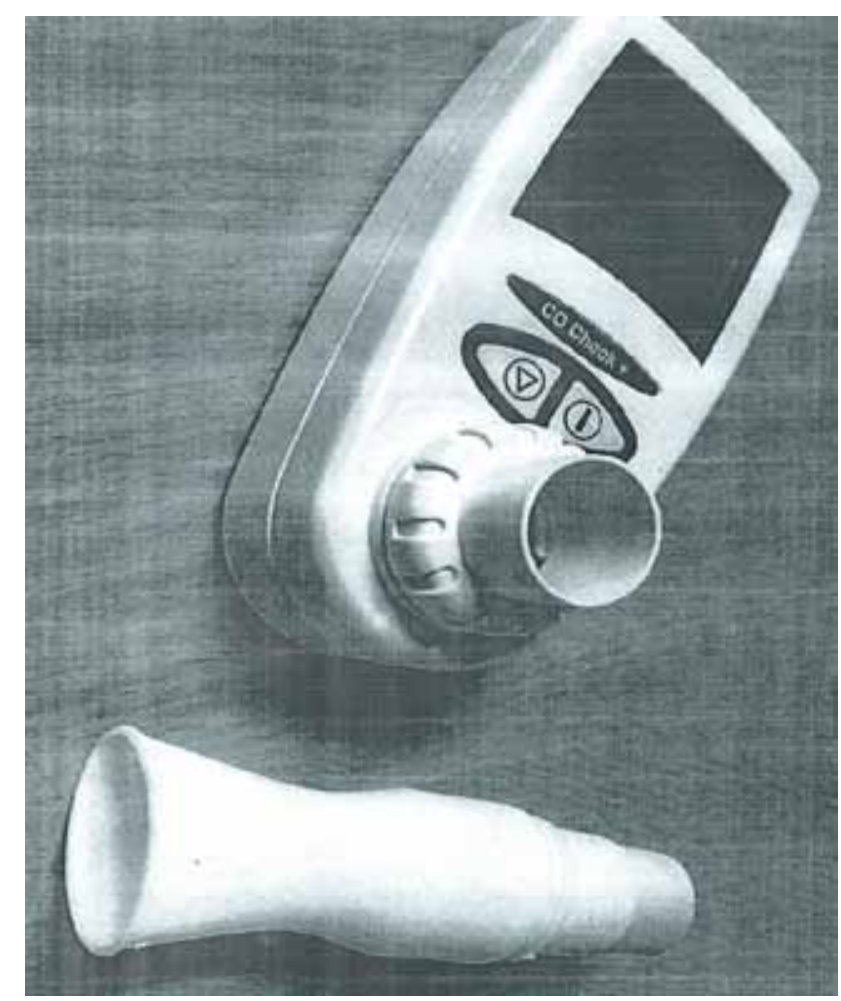

Figure 1: Carbon monoxide check plus instrument

Statistical Analysis: The results of the above tests were evaluated statistically using Statistical Package for the Social Sciences (SPSS) software version 21.

\section{Results}

The mean and standard deviation of the variable were determined for the two groups. Independent student $t$ test was employed as the Test of significance at $95 \%$ confidence interval and $\mathrm{P}$ value $<0.05$ was considered as significant.

Table 1: Comparison of $\mathrm{CO}$ in ppm in exhaled air between exposed and non exposed

\begin{tabular}{|l|l|c|c|c|c|}
\hline Variable & Group & N & Mean & SD & P value \\
\hline \multirow{2}{*}{ CO $(\mathrm{ppm})$} & Exposed & 50 & 2.78 & 1.01 & $0.145^{* *}$ \\
\cline { 2 - 6 } & Non exposed & 50 & 2.48 & 0.97 & \\
\hline \multirow{2}{*}{$* * \mathrm{p}$-value $>0.05$ not statistically significant }
\end{tabular}


Table 2: Comparison of \% $\mathrm{COHb}$ in ppm between exposed and non exposed

\begin{tabular}{|l|l|c|c|c|c|}
\hline Variable & Group & N & Mean & SD & P value \\
\hline \multirow{2}{*}{$\%$ CO Hb $(\mathrm{ppm})$} & Exposed & 50 & 0.45 & 0.17 & \multirow{2}{*}{$0.1186^{* *}$} \\
\cline { 2 - 5 } & Non exposed & 50 & 0.39 & 0.15 & \\
\hline \multirow{2}{*}{$* * \mathrm{p}$-value $>0.05$ not statistically significant }
\end{tabular}

Table 1 shows comparision of carbonmonoxide in ppm in exhaled air between exposed and non exposed to passive smoking which shows that the mean $\mathrm{CO}$ ppm in exposed group was $2.78 \pm 1.01$ and that of non exposed group was $2.48 \pm 0.97$. There was no statistically significant difference between the two groups ( -value $>0.05$ )

Table 2 shows comparision of $\% \mathrm{COHb}$ between exposed and non exposed to passive smoking which shows mean $\% \mathrm{COHb}$ was $0.45 \pm 0.17$ and that off non exposed group $0.39 \pm 0.15$. There is no statistically significant difference between the two groups(pvalue $>0.05$ ).

\section{Discussion}

Pregnant mothers fall under high risk groups. They transmit many substances to the unborn foetus compromising the outcome of the baby. These people when inhale carbon monoxide emitted from cigarette smoke passively tend to transmit the same to unborn foetus. Foetalhaemoglobin binds with carbon monoxide so that oxygen is made unavailable to foetal tissue. Exhaled air $\mathrm{CO}$ correlates better with blood $\mathrm{CO}$ percentage. Though many gold standard method are available to measure carbon monoxide levels, a non invasive simple method is used to find out the exposure to passive smoking in this study. The result of this study showed that expired air breath carbon monoxide analysis by breath monitors is less reliable in detecting exposure to passive smoking in pregnant women. In both case and control groups expired air CO levels were less than 6ppm which indicates no exposure $(2.78 \pm 1.01$ and $2.48 \pm 0.97$ respectively) and corresponding maternal blood \% $\mathrm{COHb}<0.96(0.45 \pm 0.17$ and $0.39 \pm 0.15$ respectively $)$ shows highly insignificant results. This unreliability of the test may be related to some of the physiological changes that occur during pregnancy.

The clearance of some drugs, chemicals is altered during pregnancy which results in short half- life of carbon monoxide. This narrow window for detection could be the reason for the negative results in this study (Koren $\mathrm{G}$ et al) ${ }^{17}$. The plasma half life of carbon monoxide is found to be 5 hours in air. Cotinine test is considered as most accurate method of measuring environmental tobacco exposure with longer half life about 9 hrs in pregnant women (Benowitz NL et al) ${ }^{18}$

As per the study by Frederiksen LW, Martin JE et $\mathrm{al}^{19}$ shows the longer interval between an overnight sleep and the test results in the morning could explain the negative results.

Also the relatively low levels of carbon monoxide in breath during passive smoking when compared to those of active smokers may be the reason of this unreliability. Studies by Ashford KB et $\mathrm{al}^{20}$ showed that passive exposure to smoking results in far lower levels of carbon monoxide in the breath compared with active tobacco smoking.

Thus the findings of this study confirmed that there is no difference in breath carbon monoxide levels between the study and the compared group. And the levels of carbon monoxide in exhaled air as measured by breath monitors can be considered as an invalid tool. But still this method can be used for screening smoking exposure among pregnant population and educating them to avoid further exposure to smoking environment. However further evaluation regarding the method of measurement to reduce passive smoking exposure among pregnant women; more vigorous biomarker detection tests to quantify the smoking exposure are needed ${ }^{21}$

This study population not included occupational environmental tobacco smoke exposure and domestic wood fire exposure which are other common causes of smoke; it should extend to this group too. Sometimes just eliciting history of chronic exposure to passive smoking in pregnant women will alert the primary health care personnel to reinforce the required care.

Antenatal clinic settings represent an opportunity to motivate pregnant women for avoidance of further 
smoking exposure whether passive or active. There are studies that confirm health education on the harmful effects of passive smoking was associated with a reduction of further exposure.

The limitations of this study include the use of electronic device rather than gold standard biomarkers.

\section{Conclusion}

The result of this study concludes that analysis of expired air carbon monoxidelevels by breath monitors not be useful as marker of exposure to passive smoking in pregnant women. Lesser half life of carbon monoxide, various physiological and metabolic changes associated with pregnancy, prolongedtime interval between the test and exposure might have made this test inconclusive. But in many Indian scenarios the seriousness of passive exposure of smoking usually ignored among pregnant women, thus exposing unborn foetus to various serious consequences. So non invasive portable breath monitors can be used as a tool to educate pregnant women to aware of exposure to passive smoking at earliest to avoid complications in the foetus.

\section{Conflict of Interest: No}

\section{Source of Funding: Self}

Ethical Clearance: Taken from Institutional Ethics Committee, Madras Medical College.

\section{References}

1. International Consultation on Environmental Tobacco Smoke (ETS) and Child Health, 11-14 January 1999, Geneva, Switzerland. Consultation Report. Geneva, WHO, 1999

2. Hutter CD, BlairME. Carbon monoxide-does fetal exposure cause sudden infant death syndrome? Med hypotheses 1996; 46:1-4

3. Kwak HM,Yang MH, Leems. Cytogenic effects on mouse foetus of acute and chronic transplacental in vivo exposure to carbon monoxide; Induction of micro nuclei and sister chromatid exchanges. Yonsei med J 1986: 27: 205-212

4. Leonard-Bee J, Britton J, Venn A, Second hand smoke and adverse foetal outcomes in non smoking pregnant women: A meta-analysis. Pediatrics 2011;127:734-41.

5. Fielding JE, Phenow KJ . Health effects of involuntary smoking. N Engl J Med 1988;
319:1452-60.

6. Osborne JS, Adamek S, Hobbs ME. Some components of gas components of cigarette smoke. Anal Chem 1956; 28: 211

7. Roy TS, Andrews JE, Seidler FJ, Slotkin TA. Nicotine evokes cell death in embryonic rat brain during neurulation. J Pharmacol Exp Ther 1998; 287:1136-44

8. Coburn RF, Blakemore WS, Forster RE. Endogenous carbon monoxide in man J Clin Invest 1963; 42:1172-1178.

9. Schuwey D, Tempini A, Habb P. Carbon monoxide equilibrium curve of human umbilical cord blood. Adv Exp Med Biol 1990; 277:209-214

10. Douglas CG, Haldane JS, Haldane JBS. The laws of combination of haemoglobin with carbon monoxide and oxygen. J Physiol1912; 44:275-304.

11. Turner M, Hamilton-Farrell MR, Clark RJ. Carbon monoxide poisoning: an update. J Accid Emerg Med 1999; 16:91-103.

12. Wald NJ, Idle M, Boreham J, et al. Carbon monoxide in breath inrelation to smoking and carboxyhaemoglobin levels. Thorax 1981; 36:3669.

13. Stewart RD, Stewart RS, Stamm W, et al. Rapid estimation ofcarboxyhaemoglobin levels in firefighters. JAMA 1976; 235:390-2.

14. Gomez, C (2005). "Expired air carbon monoxide concentration in mothers and their spouses above $5 \mathrm{ppm}$ is associated with decreased fetal growth". Preventive Medicine 40: 10-15.

15. Secker-Walker RH,Vacek PM, Flynn BS, Mead $\mathrm{PB}$. Exhaled carbon monoxide and urinary cotinine as measures of smoking in pregnancy, Addict Behav 1997;22:671-84

16. Bittoun R. Carbon monoxide meter: The essential clinical tool- the "stethoscope"-of smoking cessation. Journal of Smoking Cessation,2008; 3(2): 69-70.

17. Koren G. Pharmacokinetics in pregnancy; clinical significance, J Popul Their Clin pharmacol 2011; 18:e523-7

18. Benowitz NL, Jacob P,Metabolism of nicotine to cotinine studied by a dual stable isotope method. Clin pharmacol, Their 1994;56:483-93

19. Frederiksen LW, Martin JE. Carbon monoxide and smoking behavior. Addict Bebah 1979; 4:21-30 
20. Ashford KB, Hahn E, Hall L, Rayens MK, Noland $\mathrm{M}$, Collins R, Measuring prenatal secondhand smoke exposure in mother-baby couplets. Nicotine Tob Res 2010; 12:127-35.

21. Florescu A, Ferrence R, Einarson T, Selby P, Soldin
$\mathrm{O}$, Koren G. Method for quantification of exposure to cigarette smoking and environmental tobacco smoke: Focus on developmental toxicology. Ther Drug Monit 2009;31:14-30. 